\section{A RATIONAL APPROACH TO RAISED TROPONINS ON A HYPERACUTE STROKE UNIT: COPING WITH THE IMPACT ON CARDIOLOGY SERVICES}

doi:10.1136/heartjnl-2011-300198.4

S S Nijjer, G Banerjee, J Barker, S Banerjee, S Connolly, K F Fox. Imperial College Healthcare NHS Trust, London, UK

Introduction Troponin is frequently measured on admission to hyperacute stroke units (HASUs). Modest elevations in stroke are common but whether patient management changes in response to the blood test is unclear. Raised troponin without chest pain or dynamic ECG changes create diagnostic dilemmas. Management strategies were assessed with the introduction of the Imperial HASU covering North West London.

Methods Consecutive HASU admissions over 6 months were assessed for measurement of troponin, the result, and the cardiac investigations performed. Clinical parameters guided investigations lead by two Consultant Cardiologists (KF, SC) rather than strict research protocol.

Results 412 patients were admitted: 245 patients had a total of 435 troponin-I levels measured, without chest pain or dynamic ischaemic ECG changes. 70 (29\%) patients had positive levels (>0.032 ng/l): 53 (22\%) were "low" (0.032-0.3 ng/1), 17 (7\%) were "high" (>0.3 ng/l). 237 had diagnoses readily available: 170 had stroke (ischaemic or haemorrhagic), 67 had non-stroke (eg, seizure). Troponin was more likely to be raised if stroke, OR 4.3 (2.0-9.7, $\mathrm{p}=0.0001$ ). Five patients with "high" troponins had non-invasive stress testing ( 1 perfusion scan and 4 stress echos): all were negative. All positive troponins had echocardiography and cardiology review with no change in management in 91\% of cases. 6 patients had invasive coronary angiography: 3 "high" and 3 "low" troponin. Only 2 patients ( $3 \%$ of those with positive troponin) required percutaneous coronary intervention (PCI); both had troponin $>0.3$ and multiple cardiac risk factors. Patients with troponin $<0.3$ did not require PCI-all three had normal coronary arteries.

Conclusions Every positive troponin necessitated a review and additional tests, increasing demand on cardiology services without increase in resources. However only 2 patients required PCI with the majority medically managed. We propose a pragmatic pathway for when troponin is performed as a routine test. Raised troponins $>0.3 \mathrm{ng} / \mathrm{l}$ should be assessed for chest pain and ECG changes suggesting true myocardial infarction. Without these, non-invasive assessment and optimal medical therapy is sufficient in the majority. Minor troponin rise $(0.032-0.3 \mathrm{ng} / \mathrm{l})$ represents myocytolysis: cerebral insular damage causes sympathoadrenal activation and patchy myocyte damage. Without chest pain or ECG changes, optimal medical management without further investigation is appropriate. Since this does not represent true acute coronary syndrome, an early invasive strategy confers no additional benefit over medical therapy. In contrast, aspirin and statins benefit both stroke and any coronary disease present. The financial and medical implications of performing non-indicated tests in a routine manner when the result will be disregarded is significant. Therefore, we caution against routine measurement of troponin in stroke.

\section{IMPLEMENTATION OF A SENSITIVE TROPONIN I ASSAY REDUCES DEATH AND RECURRENT MYOCARDIAL INFARCTION IN PATIENTS WITH SUSPECTED ACUTE CORONARY SYNDROME}

doi:10.1136/heartjnl-2011-300198.5

${ }^{1} \mathrm{~K}$ K Lee, ${ }^{1} \mathrm{~N}$ L Mills, ${ }^{1} \mathrm{~A}$ M D Churchhouse, ${ }^{1} \mathrm{~A}$ Anand, ${ }^{1} \mathrm{D}$ Gamble, ${ }^{1} \mathrm{~A}$ Shah, ${ }^{1} \mathrm{E}$ Paterson, ${ }^{2} \mathrm{M}$ MacLeod, ${ }^{3} \mathrm{C}$ Graham, ${ }^{4} \mathrm{~S}$ Walker, ${ }^{1} \mathrm{M}$ A Denvir, ${ }^{1} \mathrm{~K}$ A A Fox, ${ }^{1} \mathrm{D}$ E Newby. ${ }^{1}$ Centre for
Cardiovascular Science, Edinburgh University, Edinburgh, UK; ${ }^{2}$ Edinburgh Heart Centre, Royal Infirmary of Edinburgh, Edinburgh, UK; ${ }^{3}$ Epidemiology and Statistics Core, Wellcome Trust Clinical Research Facility, Edinburgh, UK; ${ }^{4}$ Department of Clinical Biochemistry, Royal Infirmary of Edinburgh, Edinburgh, UK

Introduction Although troponin assays have become increasingly more sensitive, it is unclear whether further reductions in the threshold of detection for plasma troponin concentrations impact on clinical outcomes in patients with suspected acute coronary syndrome. The aim of this study was to determine whether lowering the diagnostic threshold for myocardial infarction with a sensitive troponin assay will improve clinical outcomes.

Methods Consecutive patients admitted with suspected acute coronary syndrome before ( $\mathrm{n}=1038$; validation phase) and after ( $n=1054$; implementation phase) lowering the threshold of detection for myocardial necrosis from 0.20 to $0.05 \mathrm{ng} / \mathrm{ml}$ with a sensitive troponin I assay were stratified into three groups: $<0.05,0.05-0.19$ and $\geq 0.20 \mathrm{ng} / \mathrm{ml}$. During the validation phase, only concentrations above the original diagnostic threshold of $\geq 0.20 \mathrm{ng} / \mathrm{ml}$ were reported to clinicians. Event-free survival (reinfarction and death) at 1 year were compared in patients grouped by plasma troponin concentrations.

Results Plasma troponin concentrations were $<0.05 \mathrm{ng} / \mathrm{ml}$ in 1340 (64\%), $0.05-0.19 \mathrm{ng} / \mathrm{ml}$ in 170 (8\%) and $\geq 0.20 \mathrm{ng} / \mathrm{ml}$ in $582(28 \%)$ patients. During the validation phase, $39 \%$ of patients with undisclosed plasma troponin concentrations of $0.05-0.19 \mathrm{ng} / \mathrm{ml}$ were dead or had recurrent myocardial infarction at 1 year, compared to $7 \%$ and $24 \%$ of those with troponin concentrations $<0.05 \mathrm{ng} / \mathrm{ml} \quad(\mathrm{p}<0.001)$ or $\geq 0.20 \mathrm{ng} / \mathrm{ml} \quad(\mathrm{p}=0.007)$ respectively. During the implementation phase, lowering the diagnostic threshold to $0.05 \mathrm{ng} / \mathrm{ml}$ reduced 1-year death and recurrent myocardial infarction from $39 \%$ to $21 \%$ in patients with troponin concentrations of $0.05-0.19 \mathrm{ng} / \mathrm{ml}$ (OR 0.42 , 95\%CI 0.24 to 0.84 , $\mathrm{p}=0.013$ ), whereas clinical outcomes were unchanged in patients with troponin concentrations $<0.05 \mathrm{ng} / \mathrm{ml}$ or $\geq 0.20 \mathrm{ng} / \mathrm{ml}$ (Abstract 5 figure 1).

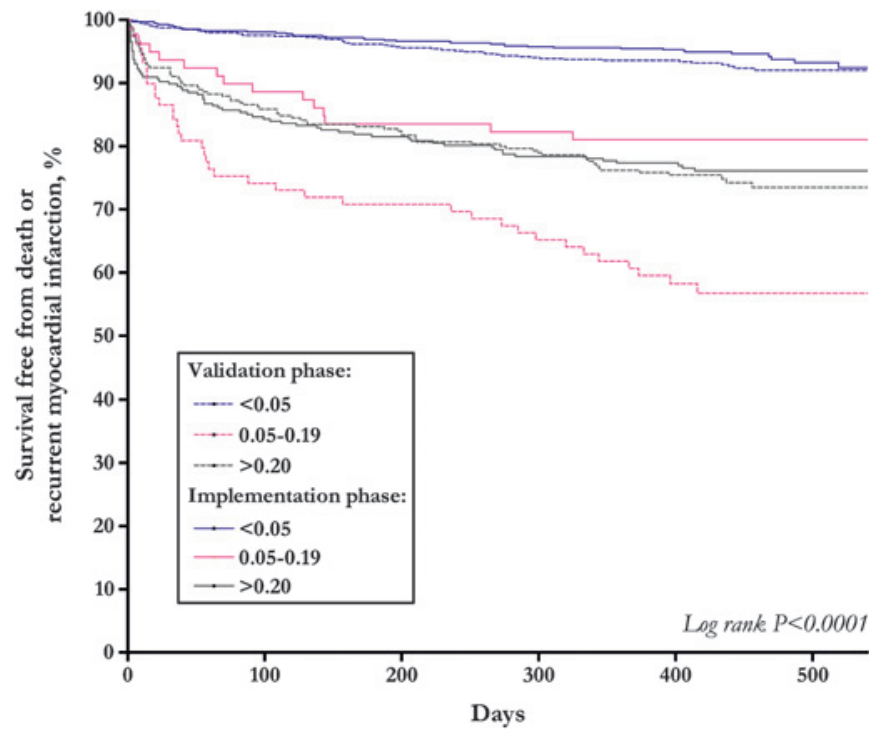

Abstract 5 Figure 1

Conclusions In patients with suspected acute coronary syndrome, implementation of a sensitive troponin assay increases the diagnosis of myocardial infarction by a third, and identifies those at high-risk of reinfarction and death. Lowering the diagnostic threshold of plasma troponin is associated with major reductions in morbidity and mortality. 